\title{
Origen y desarrollo de la editorial Espasa-Calpe Mexicana (1927-1975)
}

\author{
Juan Miguel Sánchez Vigil*
}

Artículo recibido:

10 de diciembre de 2017

Artículo aceptado:

8 de agosto de 2018

Artículo de revisión

\section{Resumen}

La comercialización del libro en América fue una de las actividades económicas que más contribuyó al desarrollo industrial español a partir de la década de los veinte del siglo pasado, especialmente en México, donde se desarrolló una ardua tarea en favor de la cultura. Una de las primeras editoriales en establecerse allí fue Espasa-Calpe, que llevó a cabo una labor excepcional en la publicación y venta de obras de autores españoles y mexicanos. Es objeto de este trabajo presentar la actividad de Espasa-Calpe Mexicana desde su origen en 1927 hasta el final de la dictadura del general Franco en 1975, analizando las distintas fases de su desarrollo con el objetivo específico de aportar nuevos datos para la historia de la edición en ambos países.

* Facultad de Ciencias de la Documentación

Universidad Complutense de Madrid, España.

$$
\text { jmvigil@ucm.es }
$$

INVESTIGACIÓN BIBLIOTECOLÓGICA, vol. 32, núm. 77, octubre/diciembre, 2018, México, ISSN: 2448-8321 pp. 31-57 
Palabras clave: Edición en México; Edición en España; Espasa-Calpe Mexicana; Industria Editorial

\title{
Origin and history of the Espasa-Calpe Mexicana
} publishing house (1927-1975)

Juan Miguel Sánchez-Vigil

\begin{abstract}
Marketing of books in America, and especially in Mexico, was an important economic activity contributing to Spain's industrial development from the 1920s forward, as it undertook the difficult task of enriching the cultural landscape. Publishing works by both Spanish and Mexican authors, Espasa-Calpe was among the first publishing houses to open in Mexico. This study provides an overview of the development of Espasa-Calpe Mexicana from its founding in 1927 until the end of the Franco dictatorship in 1975. By examining the distinct stages of its growth, this paper provides new insights into the history of publishing in both Spain and Mexico.
\end{abstract}

Keywords: Publishing in Mexico; Publishing in Spain; Espasa-Calpe Mexicana; Publishing Industry

\section{INTRODUCCIÓN}

\section{L} a industria del libro vivió un importante cambio en España a partir de 1920 cuando las grandes editoriales decidieron acometer políticas de expansión en América. La fusión de Espasa y Calpe en diciembre de 1925 convirtió a la nueva empresa en la mayor de España en fondo y volumen de negocio, con especial interés por el mercado americano, donde Calpe disponía de una delegación en Buenos Aires desde 1922.

En 1927, al tiempo que Leopoldo Calvo Sotelo publicaba Memoria sobre el libro español en América, el Consejo de Administración decidió abrir un depósito comercial en México, origen de Espasa-Calpe Mexicana. Con carácter internacional, la industria editorial tuvo numerosos altibajos si tenemos en 
cuenta que se sufrieron las dos guerras mundiales y que hasta bien entrados los sesenta no se llevaron a cabo políticas comunes que confluyeron en lo que Robert Escarpit vino en denominar en 1965 "la revolución del libro". A ello cabe añadir los problemas internos de España y de México, en ocasiones tan graves y penosos como la Guerra civil española (1936-1939).

Es objeto del artículo analizar la creación, actividad y desarrollo de la editorial Espasa-Calpe Mexicana entre 1927 y 1975, desde su creación hasta el final de la dictadura franquista, con el objetivo general de aportar nuevos datos para la historia de la edición española y mexicana en lo que se refiere a industria, comercio y situación del sector. Como objetivo específico se pretende dar a conocer a quienes hicieron posible el proyecto, poniendo en valor su aportación a la industria y cultura de ambos países.

La metodología ha sido cualitativa y cuantitativa, analizando 561 actas del Consejo de Administración de la editorial Espasa-Calpe de Madrid fechadas entre el 28 de enero de 1926 y el 28 de octubre de 1975, de las que se ha recuperado toda la información relacionada con México. Para ello se elaboró una base de datos con cuatro campos: fecha, personas citadas, temas específicos y resumen del contenido de cada documento. La lectura se ha llevado a cabo en orden cronológico, estableciendo así una estructura en tres etapas coincidentes con los momentos clave de la historia de España y de la empresa editorial: la primera desde la fundación de Espasa-Calpe (enero de 1926) hasta la Guerra civil española de 1936-1939, la segunda desde el comienzo de la posguerra hasta la constitución de la Sociedad Espasa-Calpe Mexicana (1940-1948), y la tercera durante el desarrollo de esta empresa hasta el final de la dictadura y el comienzo de la transición democrática en España (1948-1975).

Asimismo, se ha realizado una revisión bibliográfica sobre la política del libro y la edición en España y México, y se han analizado varios catálogos de la editorial en el periodo estudiado, de especial utilidad para conocer la publicación y difusión de las obras. Con el fin de contextualizar la información, se han tenido en cuenta los acontecimientos socioculturales y políticos de ambos países, y al objeto de completar el texto se han elaborado tablas explicativas sobre ventas, disponibilidades económicas y países importadores de libros. También se han incorporado reproducciones fotográficas de catálogos y libros significativos editados en España y México, procedentes del archivo de la propia editorial y de la colección del autor.

En cuanto a las fuentes, se han empleado catálogos generales de Espasa-Calpe editados entre 1937 y 1975, más varios de Espasa-Calpe Argentina y Mexicana. De ésta última han sido de gran interés los impresos en 1950 y 1954. Sobre la edición y el libro en México se han consultado las monografías 
Autores, editoriales, instituciones y libros: estudios de historia intelectual de García Diego (2015), Entre el oficio y el beneficio: el papel del editor: práctica social, normatividad y producción editorial de Kloss Fernández del Castillo (2007), y Breve historia del libro en México de Torre Villar (1999). En lo que se refiere a España las principales fuentes han sido Historia de la edición en España, coordinada por Martínez Martín (2009 y 2015), La edición en España de Sánchez Vigil (2009) y el Bosquejo de una política del libro de Gili Roig (1944). Sobre la relaciones entre ambos países se han consultado el Informe con que tropieza en varios países de la América Española la exportación de nuestros libros, editado por el Instituto Nacional del Libro Español (INLE, 1962), Los signos de la noche. De la guerra al exilio. Historia peregrina del libro republicano entre España y México de Santonja (2003) y Las relaciones entre España y México, 1810-2010 de Sánchez Andrés y Pérez Herrero (2010). La información se ha contextualizado con datos históricos tomados de Historia de México de Fernández (2008).

\section{AnteCedentes}

Desde comienzos del siglo XX los editores españoles tuvieron como objetivo desarrollar el mercado americano, entonces en manos de la industria francesa que editaba en lengua española (Martínez Rus, 2000: 32). Los años veinte comenzaron a ser fructíferos en políticas culturales, empezando con la creación en 1921 de la Oficina de Relaciones Culturales Españolas (denominada Junta de Relaciones Culturales a partir de 1926), cuyo objetivo era difundir la cultura y facilitar intercambios. En 1923 se celebró el Primer Congreso Nacional del Comercio en Ultramar donde se trató el tema del libro prioritariamente y la apertura del mercado a otros productos (Martínez Rus, 2003: 293), y en 1927 se organizó en Madrid la Conferencia Nacional del Libro para analizar los problemas editoriales.

Una de las primeras editoriales en América fue Calpe, propiedad de La Papelera Española y dirigida por Nicolás Urgoiti, quien en 1922 viajó a Buenos Aires para crear una delegación y establecer relaciones con Uruguay y Chile. Calpe formaba parte del grupo Prensa Gráfica, junto con los diarios El Sol y La Voz, las revistas Mundo Gráfico, Nuevo Mundo y La Esfera, y la librería Casa del Libro inaugurada en 1923. En diciembre de 1925 Calpe se fusionó con Espasa, editora de la Enciclopedia Universal Ilustrada, y activó el comercio en México contratando como representante a Edmundo Mas.

Hasta abril de 1927 el Consejo de Administración de Espasa-Calpe no planteó la apertura de un depósito en México, al tiempo que designó 
representantes en Cuba y Colombia para operaciones comerciales. Para desarrollar el proyecto encargaron un estudio al citado Mas, quien informó positivamente: "La situación económica por la que atravesó México entre 1924 y 1928 fue delicada. Las deudas externa e interna eran grandes y el sistema bancario inoperante" (Fernández, 2008: 59).

La editorial encargó al viajante Jacinto López Casares que realizara un periplo durante ocho meses hasta llegar a México, donde junto a Edmundo Mas debería realizar un informe con criterios de actuación. Se le adjudicó la cantidad de 3200 pesetas mensuales, más el 7 \% sobre el importe líquido de ventas del fondo de Calpe y de ediciones cuyos derechos tuviera cedidos la empresa. En carta enviada por López Casares desde El Salvador al Consejo de Administración el 29 de abril de 1928 (Acta n ${ }^{\circ}$ 29, 30 de mayo de 1928: 148), se indica que el viaje se retrasó y hasta abril de 1928 no llegó a El Salvador, donde las ventas fueron reducidas pues sólo encontró un librero interesado, M. J. Méndez. Desde allí pasó a Guatemala, y en junio se trasladó en barco a Veracruz vía La Habana.

\section{Creación y desarrollo de la delegación de MéXico (I928-I936)}

En México López Casares consiguió pedidos de dos clientes de relevancia: Andrés Botas e Hijos y Sucesores de Herrero Hermanos, e informó de la imposibilidad de visitar Guadalajara, Monterrey y Puebla debido a la Guerra cristera (1927-1929) durante la presidencia de Plutarco Elías Calles, que enfrentó a la Iglesia con el Estado. Los ingresos por venta de fondos ajenos en distribución superaron hasta casi tres veces los de los libros editados por la empresa (Tabla 1).

\begin{tabular}{|r|c|c|c|c|}
\hline \multicolumn{1}{|c|}{ Clientes } & Fondo Espasa-Calpe & Fondo ajeno & Enciclopedias & Total pesetas \\
\hline Herrero Hermanos & 3347.50 & 5446.15 & 1090 & 9883.65 \\
\hline Andrés Botas & 1565.05 & 6783.25 & & 8348.30 \\
\hline TOTAL & 4912.55 & 12229.40 & 1090 & 18231.95 \\
\hline
\end{tabular}

Tabla 1. Ventas de Jacinto López Casares en México en 1928

En abril de 1929 el Consejo de Administración decidió transformar el depósito de México en delegación, con funciones similares a Buenos Aires, poniendo al frente a López Casares temporalmente hasta que llegara desde España el primer apoderado: José Jiménez Nicolau. Los sueldos anuales fueron respectivamente de 22000 y 10000 pesetas, más un porcentaje por ventas. 
En España continuaban las iniciativas para apoyar la expansión del libro en América. En la primavera de 1929 se celebró el II Congreso Nacional del Comercio Español en Ultramar, donde se planteó que el Estado devolviera a los editores los derechos arancelarios por exportación, y que se anulara el recargo del 100 \% sobre la contribución que se pagaba. El 30 de octubre se constituyó el Consorcio Nacional de Editores Exportadores en Barcelona, cuyo objetivo fue difundir el libro español en América. Ambos eventos, junto con la creación el 14 de marzo de 1930 del Sindicato Español del Libro Español (SELE), influirían en la política comercial de Espasa-Calpe en México.

En diciembre de 1929 se procedió al alquiler de un local en el número 6 de la Avenida Isabel la Católica por un importe mensual de 175 pesos, con una inversión de 2000 pesos en acondicionamiento. La actividad dio paso a las tareas editoriales y en junio de 1930 se presentó la primera obra: Plasmogenia, de Alfonso L. Herrera, que ya había sido editada en 1924 por Herrero Hermanos y que no fue aceptada por considerarla especializada y con poca salida.

En junio de 1930 llegó a México Francisco Rubio para relevar a López Casares y dirigir la sección comercial, mientras que Jiménez Nicolau se dedicó a tareas administrativas. Las gestiones dieron excelentes resultados: se importó una remesa de libros por 40000 pesetas y aumentaron las ventas, que en 1930 alcanzaron una media mensual de 10000 pesetas. Con esas perspectivas económicas, el Consejo de Administración autorizó un viaje por el norte del país en busca de clientes. Otra de las referencias a la labor editorial fue la propuesta de publicación en noviembre de 1930 de la obra Mala yerba, de Mariano Azuela, de quien Espasa ya había editado Los de abajo.

En marzo de 1931 consiguieron las mejores ventas del año, sumando 30000 pesos a pesar de la situación del país, y en junio se realizó un estudio para determinar si el servicio de libros a Estados Unidos podría realizarse desde Cuba o México con el fin de abaratar el transporte. Finalmente se optó por seguir haciendo los envíos desde Madrid, salvo en casos solicitados expresamente por los clientes. Dato de interés es el sueldo mensual de los apoderados, fijado en 650 pesos.

Como se ha indicado, en los dos primeros semestres de 1930 y 1931 las ventas subieron considerablemente, pasando de 60877 pesetas a 412053 , con un crecimiento del $576.85 \%$. El aumento del saldo líquido por ventas de Espasa-Calpe en los primeros semestres de ese periodo también fue considerable (Tabla 2). 


\begin{tabular}{|c|c|c|c|c|c|c|}
\hline Año & \multicolumn{2}{|c|}{$\begin{array}{c}\text { Espasa-Calpe } \\
\text { Madrid }\end{array}$} & $\begin{array}{c}\text { Casa } \\
\text { del Libro }\end{array}$ & \multicolumn{2}{c|}{$\begin{array}{c}\text { Espasa-Calpe } \\
\text { Barcelona }\end{array}$} & \\
\hline & $\begin{array}{c}\text { Fondo } \\
\text { propio }\end{array}$ & $\begin{array}{c}\text { Fondo } \\
\text { ajeno }\end{array}$ & $\begin{array}{c}\text { Fondos } \\
\text { varios }\end{array}$ & $\begin{array}{c}\text { Fondo } \\
\text { propio }\end{array}$ & $\begin{array}{c}\text { Fondo } \\
\text { ajeno }\end{array}$ & Total \\
\hline 1930 & 456138.63 & 414750.80 & 392400.93 & 58953.12 & 41175.75 & 1363419.23 \\
\hline 1931 & 925449.18 & 336836.33 & 397930.10 & 58436.50 & 35798.90 & 1754451.01 \\
\hline
\end{tabular}

Tabla 2. Ventas en Espasa-Calpe (España) en los primeros semestres de 1930-1931

Consecuencia de los buenos resultados fue el aumento de sueldo a los apoderados, que en octubre de 1931 pasó a 838.50 pesos mensuales. En ello influyó el cambio de precio en la moneda efectuado por las autoridades mexicanas con arreglo al nuevo patrón de plata. En agosto de 1932 el Consejo aprobó que los apoderados se encargaran de gestionar la delegación en Cuba, elaborando informes económicos y la viabilidad para determinar acciones futuras.

En 1934 se fundó en Madrid la Agrupación de Editores Españoles con el objetivo prioritario de defender los mercados americanos. Rafael Giménez Siles, secretario de la organización, propuso depósitos comunes en varios países, iniciativa que Espasa-Calpe y otras editoriales como Aguilar llevaban realizando ya por tres lustros (Giménez Siles, 1978: 18). Durante aquel año la prioridad en México fue comercial, y se recibieron propuestas de publicación como la biografía de Francisco Morazán por Hernán Robleto en julio de 1934 para la colección "Vidas Españolas e Hispanoamericanas", que fue desestimada, o la del general López de Santa Anna de Rafael F. Muñoz, que fue informada por el historiador Melchor Fernández Almagro por su interés histórico y literario, y se publicó con una tirada de 3000 ejemplares en 1936 en la colección citada con el título Santa Anna, el que todo lo ganó y todo lo perdió.

En abril de 1935 se creó en España el Instituto del Libro Español para impulsar el comercio en América mediante nuevos depósitos. De abril a junio se recogieron en las Actas del Consejo de Administración los datos económicos, indicando las disponibilidades, entre ellas las cantidades recibidas desde las delegaciones de Buenos Aires y México. De la primera se recibieron 292204.34 pesetas y de la segunda 84245.70 pesetas, 60000 francos y 200 libras (Tabla 3). A finales de 1935 se produjo un descenso en los envíos de divisas a España (35 272.70 pesetas) que preocupó al Consejo. La justificación de los apoderados fue la situación social y la falta de suministro de obras para su venta a plazos, es decir, de libros en gran formato de alto precio, lo que hizo que durante el segundo semestre se perdieran unas 100000 pesetas de ingresos (Acta n ${ }^{\circ} 119,28$ de noviembre de 1935). 
En el primer trimestre de 1936 Espasa-Calpe Mexicana envió a la casa matriz 501264.51 pesetas, y presentó un informe de actuaciones. En abril, el apoderado Jiménez Nicolau solicitó autorización para trasladarse a España en verano debido a una afección reumática, pero la respuesta fue negativa porque según su contrato no le correspondían vacaciones. Este detalle sería anecdótico si no se hubiera producido el golpe de Estado que dio lugar a la Guerra civil en julio de 1936 y que no le permitió regresar hasta el otoño de 1939.

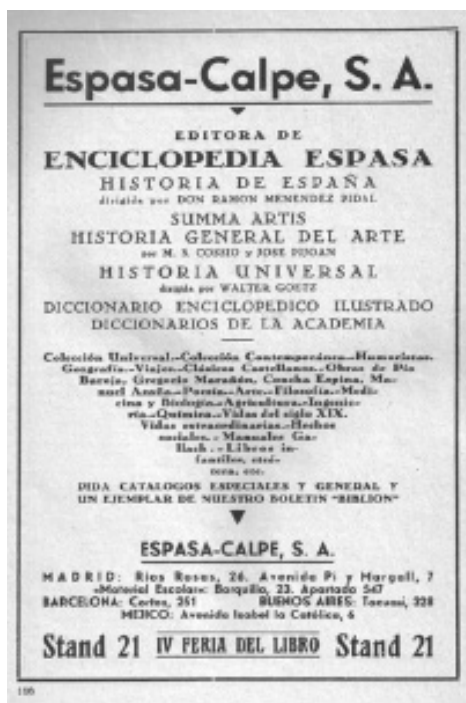

Figura 1. Publicidad de Espasa-Calpe con las direcciones de Barcelona, Buenos Aires y México (Avenida Isabel la Católica, 6). (Catálogo de la Cuarta Feria del Libro de Madrid, 1936)

\begin{tabular}{|l|r|r|r|r|}
\hline \multicolumn{1}{|c|}{ Entidad } & \multicolumn{1}{c|}{ Abril } & \multicolumn{1}{c|}{ Mayo } & \multicolumn{1}{c|}{ Junio } & \multicolumn{1}{c|}{ Julio } \\
\hline Banco de Bilbao & 1650748.94 & 823902.07 & 691553.27 & 761798.58 \\
\hline Banco de España & 3579.86 & 3381.93 & & \\
\hline Banco Popular & 393.55 & 494.95 & & \\
\hline Banco Hispano Americano & 11740.00 & 13887.93 & & \\
\hline Banco de Vizcaya & 1293.11 & 2077.11 & & \\
\hline $\begin{array}{l}\text { Banco Anglo South } \\
\text { Americano }\end{array}$ & 3983.25 & 5862.75 & & \\
\hline International Banking Corp. & 59954.67 & 163910.97 & 169015.67 & 111418.80 \\
\hline
\end{tabular}




\begin{tabular}{|c|c|c|c|c|}
\hline $\begin{array}{l}\text { Banco Mercantil } \\
\text { e Industrial }\end{array}$ & 520.45 & 520.45 & & \\
\hline Otros Bancos & & & 18094.69 & 14473.90 \\
\hline Caja de Madrid & 52235.45 & 57267.55 & 60756.34 & 68193.90 \\
\hline Caja de Barcelona & 7755.82 & 3495.53 & 2185.59 & 4045.01 \\
\hline Caja de Casa del Libro & 300.00 & 300.00 & 300.00 & 300.00 \\
\hline TOTAL & 1792505.10 & & 941905.56 & 960230.19 \\
\hline $\begin{array}{l}\text { Banco de Bilbao París } \\
\text { (Francos) }\end{array}$ & 10999.46 & 200575.26 & 23333.46 & 81569.36 \\
\hline $\begin{array}{l}\text { Banco de Bilbao Londres } \\
\text { (Libras) }\end{array}$ & $25-2-6$ & $16-3-3$ & $162-13-2$ & $349-7-2$ \\
\hline $\begin{array}{l}\text { The Anglo South American } \\
\text { Trust N. York (Dólares) }\end{array}$ & 100.24 & 220.16 & 194.88 & 406.75 \\
\hline $\begin{array}{l}\text { Deutsche Bank Leipzig } \\
\text { (Marcos) }\end{array}$ & 221.91 & 4805.16 & 1590.63 & 72.08 \\
\hline Cartera & 19850.05 & 19575.64 & 15575.00 & 9307.14 \\
\hline Recibido de Buenos Aires & 485.67 & 147936.55 & 51388.12 & 62500.00 \\
\hline Recibido de México & 40200.17 & 39730.6 & 2422.86 & $\begin{array}{r}\text { Ptas } 1892.07 \\
\text { Fran } 60000.00 \\
\text { Libras } 200.00\end{array}$ \\
\hline Valores al cobro & 174700.79 & & 136531.05 & 164953.36 \\
\hline $\begin{array}{l}\text { Importe del Dividendo } \\
\text { Activo }\end{array}$ & & 960000.0 & & \\
\hline $\begin{array}{l}\text { Pagado hasta hoy } 29.717 \\
\text { cupones }\end{array}$ & & 822566.56 & & \\
\hline $\begin{array}{l}\text { Cantidades bloqueadas } \\
\text { por envío directo en } \\
\text { pesetas }\end{array}$ & & & 100311.03 & 96897.97 \\
\hline \multicolumn{5}{|l|}{$\begin{array}{l}\text { Cantidades bloqueadas. } \\
\text { Monedas varias: }\end{array}$} \\
\hline - Chile (Pesos argentinos) & & & 673.45 & 673.45 \\
\hline - Chile (Pesos chilenos) & & & 2450.98 & 2450.98 \\
\hline $\begin{array}{l}\text { - Uruguay (Pesos oro } \\
\text { uruguayo) }\end{array}$ & & & 31995.61 & 31995.61 \\
\hline $\begin{array}{l}\text {-Uruguay (Bonos oro) } \\
\text { Francos }\end{array}$ & & & 85500.00 & 85500.00 \\
\hline
\end{tabular}

Tabla 3. Disponibilidades de Espasa-Calpe entre abril y julio de 1935

(Fuente: Actas del Consejo de Administración. Elaboración propia) 


\section{De la Guerra civil española a la constitución de la SOCIEDAd Espasa-Calpe Mexicana (1936-I948)}

Durante la Guerra civil (1936-1939) los locales de Espasa-Calpe en la calle Ríos Rosas de Madrid fueron incautados para la impresión de publicaciones oficiales. El Consejo de Administración se trasladó a San Sebastián, controlada por los golpistas, y desde allí se organizó el negocio, encargando a Manuel Olarra Garmendia, cuñado de José Jiménez Nicolau, que viajara a Buenos Aires y transformara aquella delegación en sociedad anónima debido a la gravedad de los acontecimientos en España.

El 29 de marzo de 1937 se constituyó la sociedad Espasa-Calpe Argentina y la delegación de México pasó a depender de Buenos Aires el 26 de julio mediante una operación comercial que costó a la empresa argentina 50000 pesos al contado. Fueron nombrados tres directores: Manuel Olarra, Francisco Rubio, y Gayoso, acción que se justificó para "evitar una intervención extraña en la casa mexicana, o que las disponibilidades en la misma pudieran ser objeto de un despojo" (Olarra Jiménez, 2003: 29).

Durante la contienda las relaciones con América quedaron suspendidas. A comienzos de 1937 Gonzalo Losada y Guillermo de Torre crearon en Buenos Aires la colección Austral, diseñada por Attilio Rossi, donde se publicarían las obras de autores mexicanos, entre ellos Amado Nervo, cuya Amada inmóvil llevó el número 32 y salió el 15 de enero de 1938, y Juan Ruiz de Alarcón, del que se lanzaron La verdad sospechosa y Los pechos privilegiados en el número 68, editado el 15 de mayo de 1939.
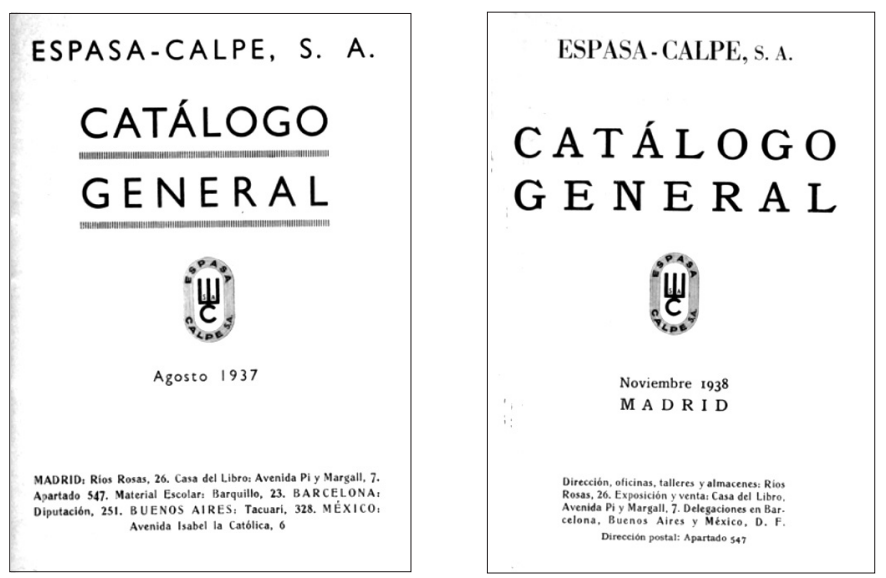

Figuras 2 y 3. Catálogos generales editados en Argentina y México durante la Guerra civil (1937-1938) 


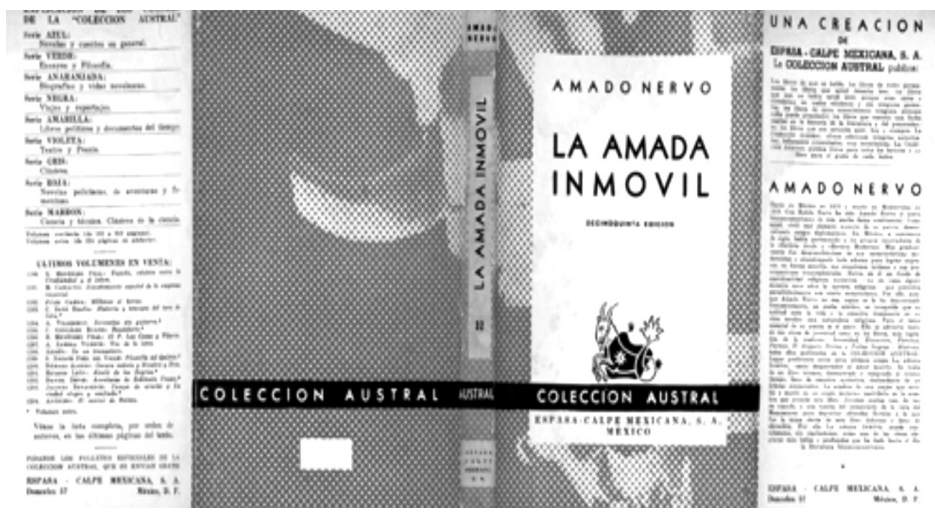

Figura 4. Amado Nervo. La amada inmóvil, Colección Austral, nº 32. Sobrecubierta de la decimoquinta edición, 1961

Como es sabido, el gobierno del presidente Cárdenas no reconoció a los golpistas españoles y acogió a los exiliados, por lo que se interrumpieron las relaciones diplomáticas. La primera Acta del Consejo de Administración después de la guerra está fechada el 31 de enero de 1940, y la primera referencia a México no aparece sino hasta el 30 de mayo, indicando que se reanudaba el servicio postal. Las ventas se controlaron desde Buenos Aires, si bien los pedidos y correspondencia se hicieron directamente con Madrid.

A partir de 1941 se atendieron los temas internos, recursos humanos y sueldos, que subieron a 210 pesos mensuales para los trabajadores. La actividad se reactivó con una gran remesa de libros que habría de llegar directamente al puerto de Veracruz una vez que se autorizara la importación. El proceso no fue fácil porque el Tesoro de EEUU prohibió la exportación y libre tráfico de efectos a los países que apoyaron a Alemania e Italia durante la Guerra Mundial: Suiza, Suecia, España, Portugal y Marruecos. En la década de los cuarenta la edición en México se impulsó con la apertura de numerosas empresas fundadas por los exiliados, En el catálogo de la exposición "Obra impresa del exilio español en México 1939/1979", celebrada entre septiembre y noviembre de 1979, se relacionan más de cuarenta empresas (Ateneo Español de México, 1979), entre ellas Edición y Distribución Iberoamericana de Publicaciones S. A. (Ediapsa), Unión Tipográfica Editorial Hispano Americana (Uteha), Grijalbo, Era, Joaquín Mortiz, Leyenda, Atlántida, Séneca o Nuestro Pueblo (Armendáriz Sánchez y Ordóñez Alonso, 1999; Fernández Moya, 2008, 2009; Ixba Alejos, 2013).

Entre los intelectuales destacó Rafael Giménez Siles, que organizó el 12 de junio de 1944, junto a Martín Luis Guzmán, la Asociación de Libreros 
y Editores Mexicanos, entidad que consiguió del presidente Manuel Ávila Camacho la exención de impuestos a la edición. En agradecimiento se creó un premio literario y científico con su nombre. Giménez Siles activó en diciembre de aquel año la primera feria del libro con el apoyo de la Sección de Editores de Libros de la Cámara Nacional de la Industria de la Transformación, inspirándose en la feria española inaugurada en 1934; concurrieron 44 empresas (Giménez Siles, 1978: 32). La segunda feria se celebraría 23 años después, el 22 de mayo de 1970, también con 44 participantes. Estos eventos coincidieron con la publicación de la conferencia de Gustavo Gili Bosquejo de una política del libro, que pronunció en Barcelona para solicitar al gobierno el apoyo al mercado en América.

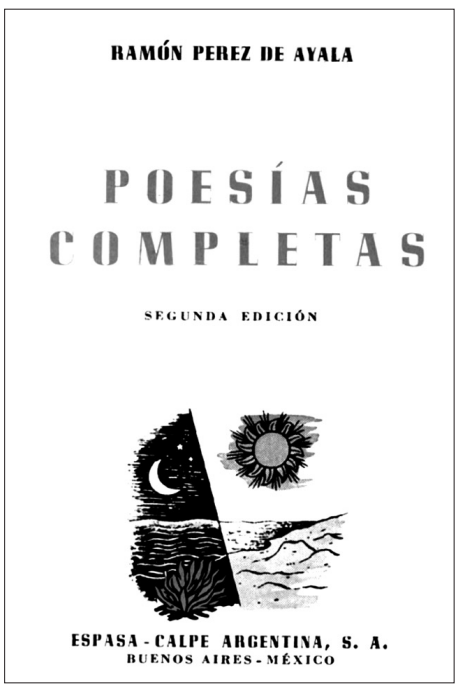

Figura 5. Segunda edición de las Poesías Completas de Pérez de Ayala. Impresa en Buenos Aires en 1942 y comercializada en Argentina, México y España

Un problema fue la piratería, denunciada en octubre de 1943 en un informe que México mandó a Madrid y Buenos Aires. Muchos libros protegidos por la Ley de Propiedad Intelectual española durante 80 años en México sólo lo estaban por 30 de acuerdo a la norma. Gran parte de los libros piratas que circulaban en México se imprimían en Argentina.

En el verano de 1944 Espasa-Calpe Mexicana se instaló en Donceles 57, edificio de amplia fachada, tres pisos y cuatro plantas, alquilado por 2300 pesos mensuales. El envío a España de ingresos se canalizó desde Buenos Aires y el informe del Consejo de Administración de 21 de diciembre de 1944 
indica que se había enviado medio millón de pesetas y que la recaudación prevista para 1945 era de otro medio millón.
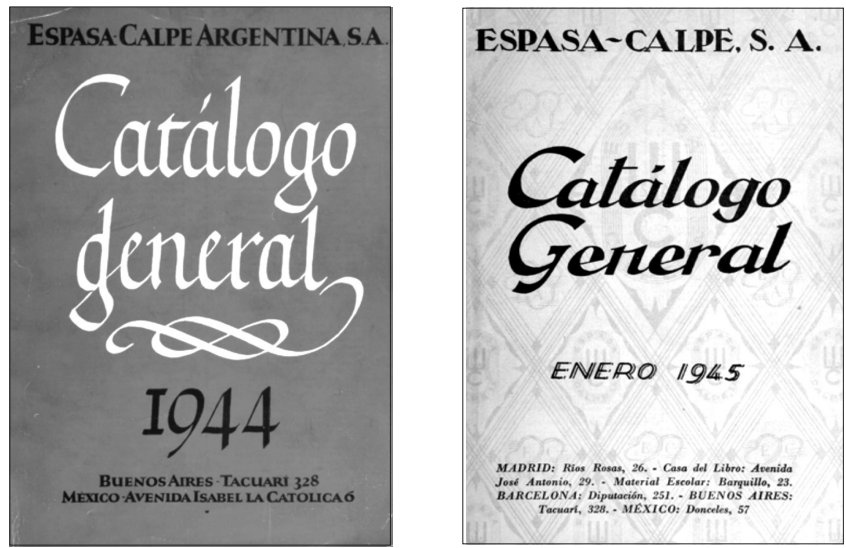

Figuras 6 y 7. Catálogos de 1944 y 1945 donde se observa el cambio de dirección de Espasa-Calpe Mexicana

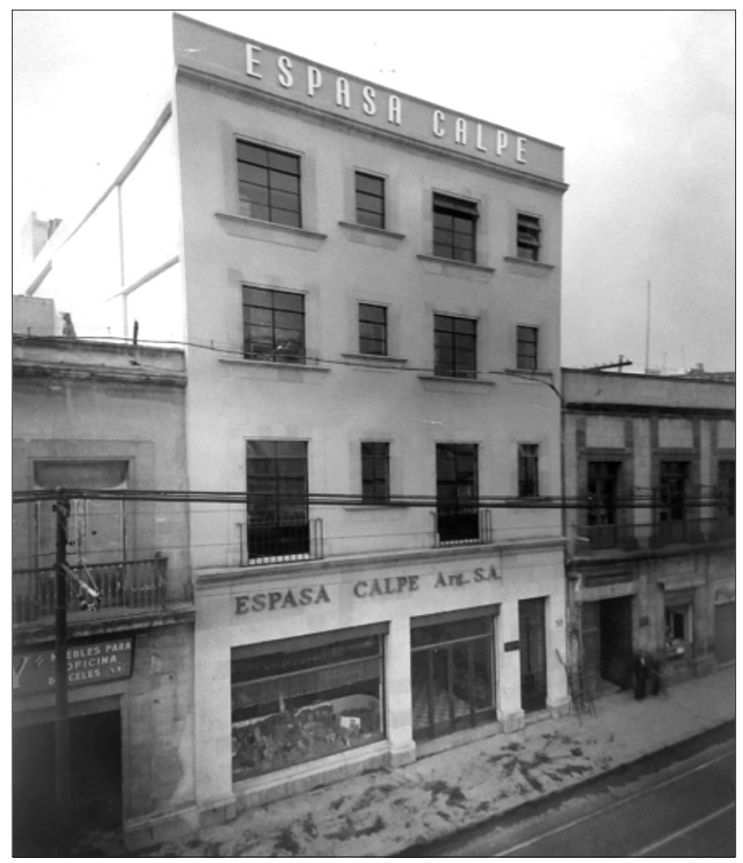

Figura 8. Edificio de Espasa-Calpe en el número 57 de la calle de Donceles, inaugurado el verano de 1944 
Al término de la Segunda Guerra Mundial, España fue expulsada de Naciones Unidas por su apoyo al fascismo, y las exportaciones de libros a México continuaron desde Buenos Aires. Sólo aquellas empresas que tenían delegaciones, entre ellas Espasa-Calpe, pudieron continuar con negocios, y en julio de 1945 Olarra viajó a México para fiscalizar la delegación y recaudar efectivo. Espasa-Calpe Mexicana comercializó las ediciones que recibía de Buenos Aires y Madrid en el mercado de Centroamérica, EEUU, Ecuador, Colombia y Venezuela. Su tarea editora fue mínima, con obras de Rafael Muñoz (Se llevaron el cañón para Bachimba, Vámonos con Pancho Villa, El águila y la serpiente), José Vasconcelos (Breve historia de México) y Salvador Novo (Nueva Grandeza Mexicana).

En 1946 se aprobó en España la Ley de Protección del Libro, con el objetivo de afrontar la carestía y conseguir papel de calidad, pero los resultados fueron malos. Ese año se produjeron tensiones políticas entre México y Argentina, reflejadas en la edición. En el artículo sin firma titulado "El auge del libro" de la revista La Propiedad (14 de septiembre) se informaba sobre el cambio positivo del momento:

La lucha editorial entablada por México en contra de Argentina y España apenas se inicia y no podemos vaticinar un éxito tan rápido y definitivo como el que se apuntó nuestro cine en su competencia contra el cine argentino y español. Solo en 1942 Argentina editó 15 millones de libros, 10 de los cuales exportó y 5 destinó a consumo interno. Entre los importadores México figuró en primer lugar adquiriendo dos millones de ejemplares impresos en Argentina, la mitad de los cuales están representados por ediciones de Espasa-Calpe [...]. México está ganando mercados exteriores al tiempo que ensancha su campo nacional. Cuba acaba de comprar el remanente de libros mexicanos de la pasada feria en 25.000 dólares y sabemos que los libreros argentinos han contratado un buen porcentaje de la producción de las más importantes casas mexicanas [...] Todo, pues, concurre a beneficiar el auge del libro mexicano: protección gubernamental, fenómenos económicos de esta postguerra, falta de transportes en el sur de América y una creciente sed de lectura en el pueblo.

En enero de 1947 se ordenó desde Madrid una valoración sobre autores de más venta, libros de éxito, precios y relación con el costo en España, papeles de impresión, posibilidades del mercado papelero y materias primas necesarias. En junio, el consejero comercial de España en Washington, Luis García Guijarro, trató de que el gobierno mexicano reconociera a Franco pero no lo logró, aunque se reabrieron varios puertos y se restablecieron relaciones económicas (Sánchez Andrés y Pérez Herrero, 2010: 37). Olarra regresó a México en noviembre para estudiar la independencia de la delegación frente a Buenos Aires, tomando como ejemplo la editorial Labor que había realizado una transformación similar. 


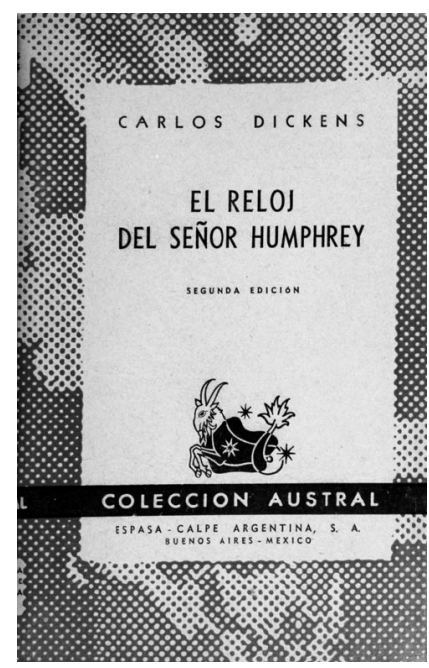

Figura 9. El reloj del señor Humphrey, de "Carlos" Dickens. Colección Austral nº 658, 2ª edición, 5 de junio de 1947

A comienzos de 1948 los apoderados se quejaron de las remesas clandestinas a bajo precio importadas a los gremios de edición y librería. Se vendieron a 15 centavos por peseta cuando el cambio oficial era de 46, situación que estaba vinculada a otras actividades: "Las importaciones se hacen movilizando pesetas en España para efectuar así una exportación clandestina de nuestra moneda a base, principalmente, de los fondos obtenidos por la exhibición de películas mexicanas en España, y también por una importante remesa de medias nylon que, al parecer, han sido introducidas en España" (Acta n ${ }^{\circ} 231,29$ de abril de 1948). Además de desvirtuar el mercado, la consecuencia fue un arancel al libro español, ya que las importaciones se consideraban dumping, práctica consistente en la venta de un producto por debajo de su precio, incluso de su coste de producción, con el fin de eliminar competencia y apoderarse del mercado.

En abril de 1948 se reestructuró la delegación para constituir una nueva sociedad. Manuel Olarra, director en Argentina, redujo el personal un 27 \%, actualizando los pagos pendientes a libreros y auditando compras y ventas. A finales de mayo de 1948 se firmó la escritura de constitución de Espasa-Calpe Mexicana y comenzó una nueva etapa. 
El 27 de mayo de 1948 se firmó la escritura de constitución de la sociedad y el 31 se redactó el acta del primer Consejo, nombrando presidente a José Izu, vicepresidente y secretario a Manuel Olarra, vocales a Antonio de Sabatés, Gervasio Collar y Manuel Quintana, y comisario a José Manuel Escobedo. Los apoderados, elegidos temporalmente mientras eran nombrados los nuevos desde España, fueron Olarra, que también ejerció de director, Francisco Rubio, Manuel G. Escobedo, y el citado Gayoso.

\section{Primera etapa, 1948-1960}

Las tensas relaciones entre México y EEUU agudizaron la crisis. El informe económico del segundo trimestre fue negativo porque el peso bajó su cotización de 6 a 4.85 con respecto al dólar. El comercio operaba con un alza del $30 \%$ en artículos importados y un $15 \%$ en nacionales, por lo que los editores tuvieron que elevar precios. En el caso de Aguilar y Espasa-Calpe se aplicó entre un 20 y un $30 \%$ de subida, que supuso una importante pérdida al convertir a dólares los créditos por venta a plazos. En septiembre el Consejo de Administración nombró a los dos nuevos apoderados: José María Mendieta, procedente de Espasa de Barcelona, y Lorenzo Salgado de Madrid, ambos con un sueldo de 1000 pesos mensuales más beneficios.

Las noticias que llegaron de México en enero de 1949 fueron las trabas del gobierno para la importación, especialmente de libros procedentes de España y Argentina, y la prohibición de entrar en el país los apoderados. Esto obligó a solicitar del director de Comercio y Política Arancelaria español, José Ibáñez Martín, que solventara las dificultades en la exportación a países americanos y especialmente a México.

Los dirigentes de Espasa en Buenos Aires y México pidieron a Madrid que la comercialización se realizara exclusivamente desde aquellas sociedades, pero se consideró inviable por las normativas de los Institutos del Libro y de la Moneda, y sobre todo porque "Los intereses de Espasa-Calpe son más y el comercio de exportación de la editorial debe supeditarse en cada momento a la conveniencia comercial que se deriva de la actual situación del comercio mundial" (Acta n ${ }^{\circ} 242,31$ de marzo de 1949).

Olarra comunicó en abril el descenso de ventas por la crisis política en México y por el impuesto del $40 \%$ sobre las importaciones. En cuanto a las publicaciones notificó la firma de un contrato para la edición de un tomo de poesías de Torres Bodet, ministro de Relaciones Exteriores y director general de Unesco, y de los libros Técnica Quirúrgica Operatoria y Dermatología, de los doctores Segovia y Bejarano. 
En mayo de 1949 se acordó pagar las cantidades adeudadas a los editores mexicanos por sus exportaciones a España a cambio de que se retirara el impuesto del $40 \%$ a los libros españoles. La intervención de Francisco Rubio ante el ministro español Ibáñez Martín fue decisiva para el desbloqueo. Los pagos a México no se realizaron con inmediatez, ya que el Instituto de la Moneda carecía de divisas en dólares, y tampoco se regularizó la importación debido al mismo problema, lo que hizo que numerosos envíos se paralizaran en la aduana de Madrid a la espera del dinero para retirarlos, situación que se normalizó en diciembre de 1949.

En enero de 1950 la empresa contaba con 34 empleados. La producción resultaba más barata en España que en México por el valor de la moneda, de ahí que se subieran los precios de la colección Austral en 50 céntimos, pasando a 3.50 pesos el volumen sencillo y a 5 el extra. El 11 de marzo de 1950 se celebró una junta general en México para el tema económico, fondos y remesas. Durante el primer cuatrimestre de ese año se observó falta de libros españoles en el mercado y la persistencia de la entrada de ejemplares piratas a mitad de precio, que influyeron concretamente en dos obras de Espasa: Diccionario Manual de la Real Academia de la Lengua y Diagnóstico Etiológico de Gregorio Marañón.

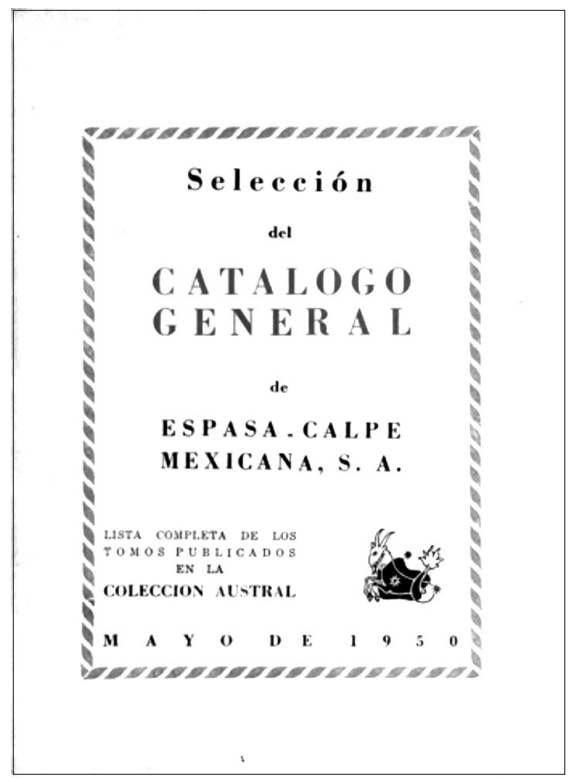

Figura 10. Catálogo general de Espasa-Calpe Mexicana publicado en mayo de 1950 
Otro problema fue la obligación de pagar en el momento de la retirada de mercancías de la aduana por imperativo del Banco Central de México, lo que suponía solicitar anticipos con intereses. Debido a esto desde abril quedaron retenidas 130 cajas de libros y 1970 paquetes, retirados a medida de las necesidades mediante pagos fraccionados.

Las tensiones políticas entre México y Argentina habían paralizado la actividad durante dos años, que se reanudó en julio de 1950 con reimpresiones de obras agotadas, fundamentalmente de la colección Austral, de cuyas tiradas la mitad de ejemplares eran remitidos a Buenos Aires. En el catálogo impreso en mayo de ese año se incluyó la colección "Libros de Historia Mexicana" con 11 títulos.

El gobierno mexicano dificultó la importación de libros españoles y por temor a otro impuesto se procedió a enviar fondos desde Madrid, sobre todo tomos de la Enciclopedia Espasa y de grandes obras, porque "del resto del catálogo se encuentran surtidos, ya que en esas remesas que acaban de retirar se forzó mucho el envío de todos los títulos de que carecían o que estaban a punto de que se les agotaran" (Acta 258, 22 de julio de 1950). Los problemas se agudizaron y un cargamento preparado en el puerto de Bilbao fue retenido al conocer que el gobierno mexicano exigía licencia de importación. Finalmente el barco salió en diciembre hacia Veracruz, y al mismo tiempo se realizó una exportación por correo, si bien con el temor de que fuera retenida en la aduana al no aceptar el cambio libre español para las importaciones y exportaciones de libros fijado por el Instituto de la Moneda.

En marzo de 1951 Olarra realizó una revisión de la delegación y convocó una junta general. La situación en México era buena pero no en Buenos Aires debido a la escasez de papel, hasta el punto de que varios libros maquetados quedaron sin imprimir. En junio se activó el convenio de importación entre México y España, y en marzo de 1952 el apoderado Francisco Rubio enfermó y fue trasladado a una clínica de Nueva York donde falleció dos meses después. Mendieta y Salgado continuaron su labor.

Entre mayo de 1953 y julio de 1954 se generaron deudas en Espasa Argentina por valor de 2500000 de pesos. La reacción del Consejo de Administración de Madrid para corregir la gestión fue intensificar las ventas y restringir publicaciones. El Consejo aprobó que las filiales mexicana y argentina obraran como delegaciones de la sociedad de Madrid, procurando que se editara en España salvo excepciones (Acta n ${ }^{\circ} 307,30$ de agosto de 1954). En agosto de 1954 el apoderado Lorenzo Salgado, de vacaciones en España, expuso que la situación de la sociedad era excelente y perfectamente saneada. 
Sin embargo, la situación empeoró en Buenos Aires y en octubre de 1954 la deuda con Espasa México aumentó en 45115 pesos, correspondiente a libros editados en México y enviados a Argentina. El Consejo decidió entonces ceder protagonismo a la editorial mexicana:

En nuestro deseo delimitar la actuación de Espasa Calpe Argentina, se han pasado reediciones de Austral y de obras varias a México, pero si como consecuencia de ello Argentina cursa sus pedidos por las obras cuya reimpresión ha llevado a cabo México, y no satisface su importe, no se consigue nuestro propósito, antes al contrario, se coloca a Argentina en una situación privilegiada, puesto que no tiene que desembolsar cantidades por tales reediciones. En su consecuencia el Consejo acordó se escriba a Espasa Calpe Mexicana y Argentina, en el sentido de que, en adelante, se abstendría México de remitir libros a Argentina, a no ser que ésta haya satisfecho con anterioridad una cantidad igual a los libros que solicite, a fin de que no aumente la deuda que ya tiene contraída. (Acta n ${ }^{\circ} 333,20$ de diciembre de 1954)

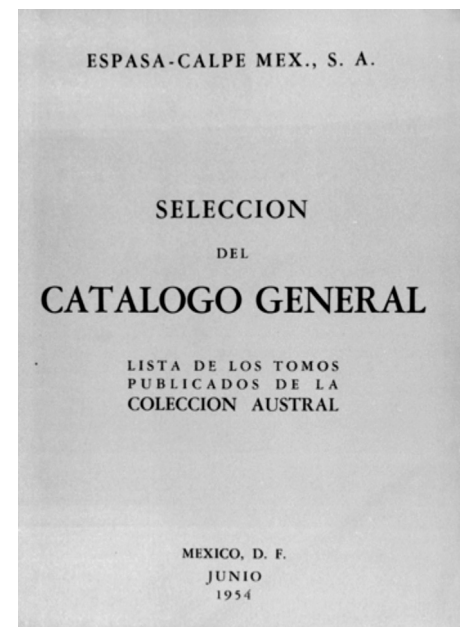

Figura 11. Catálogo de junio de 1954

La comercialización en Buenos Aires mejoró en el último trimestre de 1954. En cuanto a México, el balance se consideró satisfactorio y se autorizó el viaje de Mendieta a España para que informara. A su regreso consiguió un aumento de sueldo del 10 \% para los empleados, pasando la nómina mensual de la sociedad de 11975 a 13337.50 pesos. En relación a los apoderados, la devaluación del peso mexicano de 5.20 a 3.10 pesetas les había supuesto una disminución en sus ingresos de 825 pesetas por cada 100000 pesos mexicanos de venta líquida. El Consejo acordó en febrero de 1955 acceder a una mejora de 2000 pesos, con una comisión por ventas de entre el 2.25 y el $2.50 \%$. 
En 1956, año en que España reingresó en la ONU por mediación de EEUU, Rafael Giménez Siles fundó la Agrupación de Editores Mexicanos con la participación de 13 entidades, presidida por él mismo y por Luis Novaro (Giménez Siles, 1978: 33). La economía se reactivó y en abril los pedidos a Madrid superaron los 2 000, entre ellos 250 colecciones del Diccionario Enciclopédico Abreviado de Espasa en 7 tomos. Sin embargo, el Consejo había restringido al máximo las ediciones en las dos filiales durante 1955 y 1956 con una sola novedad, más 42 títulos de Austral (25 en 1955 y 17 en 1956).

En mayo de 1957 la nómina mensual total pasó de 12985 pesos a 14 930, es decir, un $15 \%$ más, y a los apoderados se les concedió una retribución fija de 500 pesos mensuales. México saldó con Argentina una parte de la deuda contraída, abonando 7757 pesos. Las ventas experimentaron una baja debido a la convocatoria de elecciones presidenciales y a la carencia de nuevas obras para venta a plazos. En consecuencia, el Consejo resolvió que se editaran los libros de autores mexicanos de interés.

A comienzos de 1958 los editores españoles denunciaron el convenio bibliográfico con México y las exportaciones de libros quedaron suspendidas temporalmente. Esto afectó las ventas puesto que se acusó la carencia de títulos, como informó el apoderado Mendieta durante su estancia en Bilbao. También fue un contratiempo la decisión de la editorial Aguilar, que retiró la exclusiva de comercialización de sus libros a las dos filiales americanas. Afortunadamente, el convenio se prorrogó hasta enero de 1959 y se reanudó el envío. Con el fin de recuperar mercado se ordenó desde Madrid que se reimprimieran títulos de Austral de autores argentinos y mexicanos, y que se revisaran los libros recomendados como texto en las escuelas, así como los de autores españoles que por circunstancias excepcionales no podían editarse en España, en clara alusión a cuestiones de derechos y a temas políticos.

Las ventas de 1959 arrojaron cifras inferiores a las de 1958, pero no así los cobros. A la reducción de ingresos se sumó la subida de sueldos por disposición gubernamental, pasando el salario mínimo de 12.50 pesos diarios a 14.50 , si bien la editorial decidió abonar 14.75 para que los trabajadores se acostumbraran a pagar su parte del seguro.

\section{Segunda etapa, 1961-1975}

En 1960 la incertidumbre fue remitiendo. Los ingresos subieron debido a la diferencia en el cambio de moneda, que pasó de 3.10 pesos a 4.80. A finales de ese año la comisión para los apoderados pasó del 2.5 al $3 \%$, sin alteración en los sueldos, mientras que el de Olarra aumentó de 11260 pesos a 15000. Se observa la desigualdad de trato a los dirigentes de ambas filiales, sobre 
todo tras la advertencia del Consejo de Espasa-Calpe a Olarra advirtiéndole que "debía procurar por todos los medios enviar a España, aunque sólo sea en parte, los beneficios que obtenga, ya que ese fue el motivo y fundamento de establecer las delegaciones y no limitarse simplemente al pago de las facturas de los libros que le son remitidos" (Acta n ${ }^{\circ} 391,30$ de agosto de 1961). El año 1961 fue de "normalidad" según manifestó Salgado al Consejo. Desde México se importaron varios títulos de Austral que fueron importante fuente de ingresos.

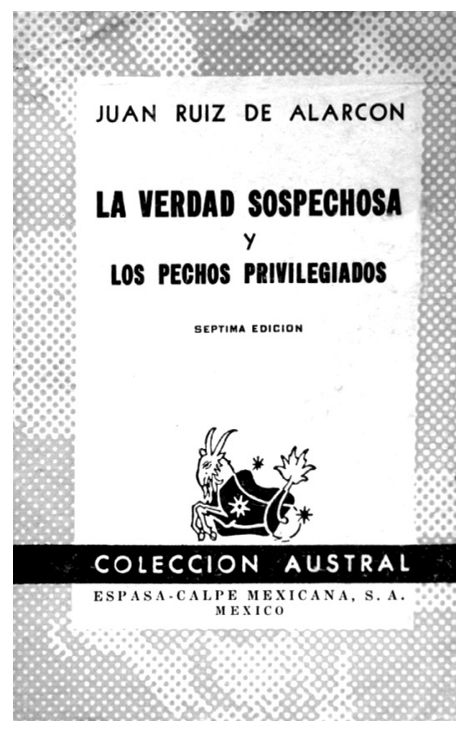

Figura 12. La verdad sospechosa y Los pechos privilegiados, de Juan Ruiz de Alarcón. Colección Austral, nº 68, 7ª edición, 4 de septiembre de 1959

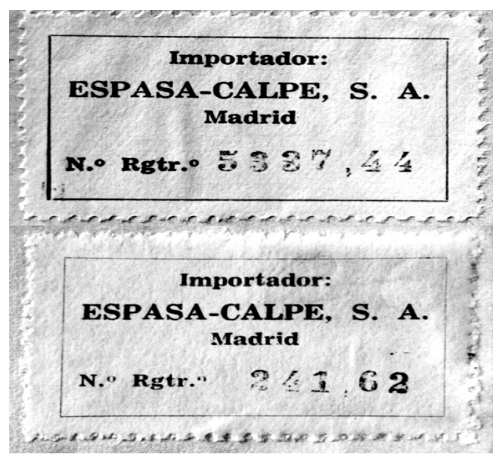

Figura 13. Sellos de Espasa-Calpe de Madrid en ejemplares de la colección Austral importados de México en 1961 
El informe del Instituto Nacional del Libro Español de 1962 señalaba una fuerte competencia y la exclusión de España en los proyectos mexicanos de coedición. El precio fue un problema debido a los costos de fabricación en España y a los márgenes de distribución, y en cuanto a la política arancelaria española el gravamen sobre el papel complicaba la situación. El transporte se realizaba en barco con una media de recepción de dos a tres meses, por ello era necesario hacer grandes pedidos cuyos pagos se realizaban mediante préstamos (INLE, 1962). En el primer semestre se produjo un descenso en las ventas y a finales de año el mercado era estacionario.

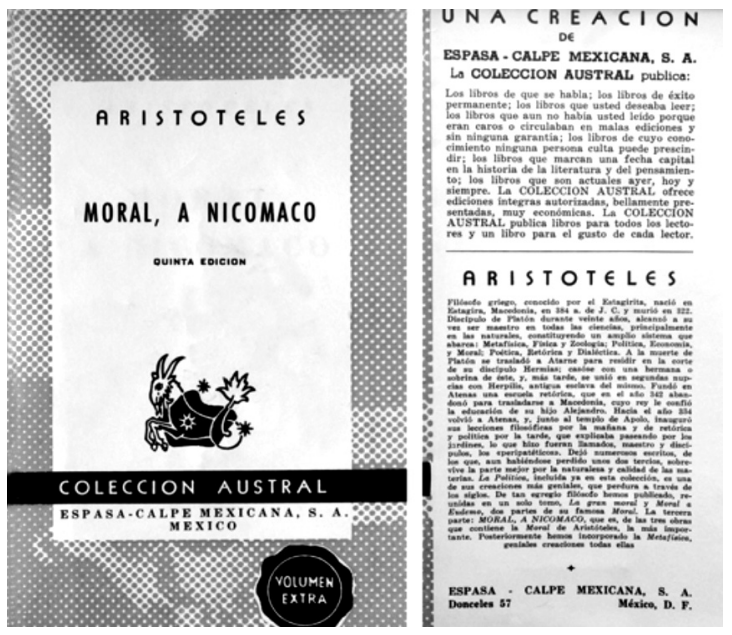

Figura 14. Aristóteles. Moral a Nicómaco. Cubierta y solapa. Colección Austral, n 318, 5ª edición, 1962

En 1963 las actas del Consejo no reflejaron incidencias notables y el informe corrió a cargo del omnipresente Olarra. En 1964 se celebró en la capital mexicana el Primer Congreso Iberoamericano de Asociaciones y Cámaras del Libro del 18 al 23 de mayo. El representante español fue Carlos Robles Piquer, presidente del INLE, y se tomaron lo siguientes acuerdos: libre exportación por vía aérea, mayor divulgación y distribución de los libros, e instauración del Día del Libro Iberoamericano el 23 de abril.

La actividad de 1965 fue regular, y a mediados de 1966 se realizó un pedido a Madrid por importe de 4950000 pesetas. Durante 1967 y 1968 en los informes llegados desde México se empleó el término "normalidad". En dos años se estudió la unificación de instalaciones en el local de Avenida de la Morena, dejando las oficinas de Donceles y los almacenes y talleres de las calles Sidar y Rovirosa. El cambio se llevó a cabo en septiembre de 1969, al tiempo que la reestructuración de la empresa, fijando para los apoderados un sueldo de 44500 pesos anuales y una comisión por ventas del 3 al $4 \%$. 
México fue, tras Argentina, el principal importador de libros españoles entre 1968 y 1970, y el primero en 1971. Venezuela, Chile y Colombia fueron los otros grandes compradores, y en menor medida Puerto Rico, Uruguay, Estados Unidos y Brasil. Entre los países europeos, sólo Francia y Reino Unido se interesaron por la edición española (Tabla 4).

\begin{tabular}{|l|c|c|c|c|}
\hline \multicolumn{1}{|c|}{ ORDEN } & 1968 & 1969 & 1970 & 1971 \\
\hline 1 & Argentina & Argentina & Argentina & México \\
\hline 2 & México & México & México & Argentina \\
\hline 3 & Venezuela & Venezuela & Venezuela & Venezuela \\
\hline 4 & Chile & Chile & Colombia & Colombia \\
\hline 5 & Colombia & Colombia & Chile & Francia \\
\hline 6 & Perú & Francia & Francia & Chile \\
\hline 7 & EE.UU & Cuba & Reino Unido & Reino Unido \\
\hline 8 & Puerto Rico & EE.UU & Puerto Rico & Uruguay \\
\hline 9 & Brasil & Perú & EE.UU & EE.UU \\
\hline 10 & Uruguay & Puerto Rico & Perú & Perú \\
\hline
\end{tabular}

Tabla 4. Países con mayor compra de libros españoles entre 1968 y 1971

Fuente: Cendán Pazos (1972: 153)

En agosto de 1970 se realizó una operación de envergadura firmada tras un viaje urgente del apoderado Salgado para estudiar con Ernesto Antón, director general de Espasa-Calpe, la venta a los almacenes Aurrerá de 15000 ejemplares del Diccionario Enciclopédico Abreviado, 5000 de ellos encuadernados en cartoné y 10000 en tela. En los dos años siguientes la delegación acumuló deudas con la casa central por el impago de las remesas. En mayo de 1972 se tomó la decisión de cortar el suministro de libros a México si el tema no se solucionaba, con gran preocupación del Consejo. En diciembre el apoderado Salgado fue relevado del cargo tras 24 años de servicio y se le autorizó a regresar a España. Fue sustituido por Francisco Cruz Rubio en enero de 1973, quien trabajaba en la Secretaría de Ediciones de Madrid, con 44500 pesos de sueldo anuales más una comisión del 3 \% sobre ventas. Sus primeras tareas fueron supervisar la auditoría de la empresa Price Waterhouse y regularizar el capital de la sociedad, que pasó a un millón de pesos después de la gestión realizada ante la Dirección General de Transacciones Exteriores del Ministerio de Comercio, aprobada en Consejo de Ministros el 23 de noviembre de 1973. 
Fue este un momento de expansión derivado del decreto de 1971 por el que el Gobierno español actualizaba la Ley de Protección del Libro de 1946, con objeto de facilitar la importación de papel, bajar el gravamen fiscal por exportación y mejorar las condiciones de financiación. Con estas medidas aumentó la industria editorial española, pasando del trigésimo puesto que ocupaba en el ranking editorial mundial en 1949 al quinto lugar en 1974.

El desequilibro en la balanza de exportaciones con América llevó al gobierno mexicano a tomar medidas, y a instancias de la Cámara Nacional de la Industria Editorial Mexicana se limitó la importación a un máximo de 1500 ejemplares por título, de forma que las empresas extranjeras se vieran obligadas a editar en el país y creciera así el empleo en el sector de artes gráficas.

Las actas del Consejo de Administración de Espasa-Calpe de Madrid en 1974 y 1975 apenas hacen referencia a México. En julio de este último año se produjo un incremento de las ventas del $38 \%$, pero se interrumpió al cerrarse las fronteras a las importaciones. Las previsiones de importación desde México para 1976 se fijaron en dos millones de pesos (diez millones de pesetas), pero para obtener la autorización oficial se debía exportar con anticipación por el mismo valor. El comercio se paralizó y en octubre de 1975 se informó que el stock se iba agotando y las posibilidades de venta descendían. Con esta perspectiva, el 20 de noviembre murió el general Franco en Madrid y comenzó el cambio democrático. Dos años después, en 1977, la administración del presidente López Portillo reanudó las relaciones diplomáticas con España tras casi 40 años de silencio. La historia tomó otro rumbo.

\section{Conclusiones}

Con carácter general, se concluye que la conservación de la documentación de las empresas editoriales es fundamental para el estudio y análisis de la historia de la edición. En el caso que nos ocupa se han localizado las actas del Consejo de Administración de Espasa-Calpe, los catálogos editoriales y varias fotografías procedentes de su archivo. En consecuencia, consideramos que las administraciones públicas deben establecer políticas, protocolos y normativas que garanticen su preservación, partiendo de la adquisición de los archivos editoriales para su posterior tratamiento documental.

La documentación editorial, y en particular las actas de Espasa-Calpe, nos permiten conocer la estructura y funcionamiento interno de la empresa en el periodo de análisis, ya que ofrece información sobre la composición y decisiones de los consejos y comités directivos, tanto en lo que se refiere a la administración como a las obras editadas. 
El corpus que aquí se analiza constituye un referente para conocer las relaciones internacionales en cuanto a la industria del libro, así como las políticas para su producción y comercialización. Es por tanto una fuente de información imprescindible para conocer las actividades españolas sobre la expansión del libro en América, partiendo de tres actuaciones específicas: la celebración del II Congreso Nacional del Comercio en Ultramar (1929), la creación del Consorcio Nacional de Editores Exportadores de Barcelona (1929) y la fundación del Sindicato Español del Libro Español (1930). Por otra parte, se ponen de relieve los problemas para la comercialización de los libros en México: los aranceles por exportación, la piratería o falta de respeto a los derechos de autor, y las diferencias en cuanto a la protección de la propiedad intelectual (30 años después de la muerte del autor en México y 80 en España).

Las delegaciones de la editorial en México, Argentina y España, en especial en la década de los cincuenta, aumentaron la producción y generaron un flujo comercial mediante el intercambio de libros en función de las necesidades de cada país. Queda patente la relación cultural y comercial entre Espasa-Calpe Argentina y Mexicana, realizando actividades de compensación para acometer los problemas de una y otra empresa. Las referencias concretas nos permiten conocer los momentos críticos en lo que se refiere a las economías mexicana y argentina, así como a las políticas del libro. Si en un primer momento la empresa mexicana dependió de la delegación de Buenos Aires, su constitución en sociedad en 1948 la transformó en una entidad clave para la casa central, tanto desde el punto de vista económico como cultural al editar obras de autores mexicanos, especialmente en la colección Austral.

Por lo que respecta a la propia actividad de Espasa-Calpe Mexicana, se concluye que su papel fue decisivo para la industria del libro en España y México, como se observa en las referencias al volumen de negocio y a los movimientos de capital de la empresa. Su contribución al desarrollo de la economía española mediante el envío de recursos es un hecho, fundamentalmente en las tres décadas posteriores a la Guerra Civil española de 1936-1939. Fue también base de la industria generada por la empresa matriz durante la posguerra, en los momentos críticos de la economía española.

Por último, con esta investigación se pone en valor la aportación de la editorial Espasa-Calpe a la cultura y se aportan nuevos datos para la historia de la edición en México y España, destacando la labor de aquellos intelectuales y profesionales que dirigieron la empresa durante medio siglo entre 1927 y 1975, especialmente Manuel Olarra Garmendia, José Jiménez Nicolau y Francisco Rubio. 


\section{REFERENCIAS}

Armendáriz Sánchez, Saúl y Magdalena Ordóñez Alonso. 1999. "La aportación de los refugiados españoles a la bibliotecología mexicana: notas para su estudio". Proyecto Clio 8. Fecha de consulta: 24 de septiembre de 2016. http://clio.rediris. es/pdf/exilio.pdf

Ateneo Español de México. 1979. Obra impresa del exilio español en México 1939/1979. Catálogo de la exposición. México: Inbad/Sep.

“Auge del libro, El”. 1946. La Propiedad, México, 14 de septiembre, en Editor, librero e impresor. Guión autobiográfico profesional, Rafael Giménez Siles, 125. México: Impresora Azteca, 1978.

Calvo Sotelo, L. 1927. El libro español en América. Madrid: Gráfica Universal.

Cendán Pazos, Fernando. 1972. Edición y comercio del Libro Española, 1900-1972. Madrid: Editora Nacional.

Escarpit, Robert. 1965. La revolución del libro. Madrid: Alianza Editorial.

Fernández, Iñigo. 2008. Historia de México. México: Panorama Editorial.

Fernández Moya, María. 2009. "Editoriales españolas en América Latina. Un proceso de internacionalización secular". Información Comercial Española. Cuadernos económicos 848 (julio-agosto): 65-77.

Fernández Moya, María. 2008. "Editores españoles a ambos lados del Atlántico: el sector editorial republicano y la edición en la España franquista”. Historia del presente 12 (España): 97-110.

García Diego, Javier. 2015. Autores, editoriales, instituciones y libros: estudios de bistoria intelectual. México: El Colegio de México.

Gili Roig, Gaspar. 1944. Bosquejo de una política del libro. Barcelona: Hispano Americana.

Giménez Siles, Rafael. 1978. Editor, Librero e Impresor. Guión autobiográfico profesional. México: Imprenta Azteca.

INLE (Instituto Nacional del Libro Español). 1962. Informe sobre las dificultades con que tropieza en varios países de la América Española la exportación de nuestros libros, 22 de noviembre de 1962. Archivo General de la Administración, Cultura, Expediente 73-000475.

Ixba Alejos, Elizer. 2013. "La creación del libro de texto gratuito en México (1959) y su impacto en la industria editorial de su tiempo: Autores y editoriales de ascendencia española”. Revista Mexicana de Investigación Educativa 18 (59): 1-19.

Kloss Fernández del Castillo, Gerardo. 2007. Entre el oficio y el beneficio: el papel del editor: práctica social, normatividad y producción editorial. Guadalajara: Universidad de Guadalajara y Santillana Editorial.

Martínez Martín, Jesús Antonio, coord. 2015. Historia de la edición en España, 19391975. Madrid: Marcial Pons.

Martínez Martín, Jesús Antonio. 2009. Historia de la edición en España, 1836-1936. Madrid: Marcial Pons.

Martínez Rus, Ana. 2003. La política del libro durante la Segunda República. Socialización de la lectura. Gijón: Trea.

Martínez Rus, Ana. 2000. "La proyección editorial en los mercados americanos (1901-1936)". Pliegos de Bibliofilia 12 (4º trimestre): 31-53. 
Olarra Jiménez, Rafael. 2003. Espasa-Calpe. Manuel Olarra, un editor con vocación americana. Buenos Aires: Dunken.

Sánchez Andrés, Agustín y Pedro Pérez Herrero. 2010. Las relaciones entre España y México, 1820-2010. Madrid: Real Instituto Elcano.

Sánchez Vigil, Juan Miguel. 2009. La edición en España. Industria cultural por excelencia. Historia, proceso, gestión, documentación. Gijón: Trea.

Sánchez Vigil, Juan Miguel. 2005. Calpe. Paradigma editorial. Gijón: Trea.

Santonja, Gonzalo. 2003. Los signos de la noche. De la guerra al exilio. Historia peregrina del libro republicano entre España y México. Madrid: Castalia.

Torre Villar, Ernesto de la. 1999. Breve historia del libro en México. México: Universidad Nacional Autónoma de México.

Para citar este texto:

Sánchez Vigil, Juan Miguel. 2018. “Origen y desarrollo de la editorial Espasa-Calpe Mexicana (1927-1975)”. Investigación Bibliotecológica: archivonomía, bibliotecología e información 32 (77): 31-57.

http://dx.doi.org/10.22201/iibi.24488321xe.2018.77.57896 